\title{
OS PONTOS, OS FIOS E NÓS: A LITERATURA COMO UM DIREITO
}

The stitches, the threads and the knots (we): the literature as a right

Los puntos, los hilos y nosotros: la literatura como derecho

\section{Izandra Alves ${ }^{1}$, Natália Branchi de Oliveira ${ }^{2}$, Luana Paula Maldaner ${ }^{3}$}

\section{RESUMO}

Este artigo se propõe a desenvolver uma reflexão acerca de uma ação artístico-literária realizada com meninos privados de liberdade, do Centro de Atendimento Socioeducativo de Caxias do Sul/RS, e com estudantes do ensino básico que estudavam remotamente, durante a pandemia do coronavírus. Baseando-se, principalmente, nas teorias de Michelè Petit (2009), acerca do papel que a leitura exerce nos espaços de crise, e na concepção de literatura como direito universal, de Antonio Candido (2011), realizamos ações leitoras valendo-nos dos textos E agora José?, de Carlos Drummond de Andrade, e O espelho, de Machado de Assis. Como produção a partir da mediação leitora, cada adolescente bordou, em um pequeno pano, uma frase que mais lhe tocou dos textos, ou que criou a partir deles. Assim, unindo pano a pano, compusemos o grande mosaico de pontos, fios e nós da quarentena.

Palavras-chave: Extensão; Leitura; Espaços de crise; Bordado.

\footnotetext{
1 Doutora em Letras pela Universidade de Passo Fundo; Professora de Língua Portuguesa, Língua Espanhola e Literatura, no Instituto Federal de Educação, Ciência e Tecnologia do Rio Grande do Sul - Campus Feliz.

${ }^{23}$ Acadêmicas do Curso de Licenciatura em Letras Português e Inglês do Instituto Federal de Educação Ciência e Tecnologia do Rio Grande do Sul, Campus Feliz.
} 


\section{ABSTRACT}

This article intends to develop a reflection on an artistic-literary action carried out with boys deprived of their liberty, from the Centro de Atendimento Socioeducativo de Caxias do Sul / RS, and with primary school students who studied remotely, during the coronavirus pandemic. Based mainly on the theories of Michèle Petit (2009), about the role that reading plays in crisis spaces, and on the concept of literature as universal right, by Antonio Candido (2011), we carry out reading actions using the texts E agora José?, by Carlos Drummond de Andrade, and O Espelho, by Machado de Assis. As a production based on reading mediation, each adolescent embroidered, on a small cloth, a phrase that most touched him from the texts, or that he created from them. Thus, joining cloth to cloth, we composed the large mosaic of stitches, threads and the knots from the quarantine.

Keywords: Extension. Reading; Crisis spaces; Embroidery.

\section{RESUMEN}

Este texto desarrolla una reflexión acerca de una acción artístico-literaria realizada con jóvenes privados de libertad, del Centro de Atendimento Socioeducativo de Caxias do Sul / RS, y con estudiantes de primaria que tomaron clases a distancia en período de la pandemia del coronavírus. Siguiendo, principalmente, las teorías de Michelè Petit (2009), sobre el papel que tiene la lectura en los llamados espacios de crisis, y sobre el concepto de literatura como un derecho universal, de Antonio Candido (2011), realizamos la acción de lectura basándonos en los textos E agora José?, de Carlos Drummond de Andrade, y O Espelho, de Machado de Assis. Como producción artístico-literaria basada en la mediación lectora, cada jóven bordó, en una pequeña tela, una frase que más les tocó de los textos, o que creó a partir de ellos. Así, uniendo tela con tela, compusimos el gran mosaico de puntos, hilos y nudos de la cuarentena.

Palabras clave: Extensión; Lectura; Espacios de crisis; Bordado. 


\section{INTRODUÇÃO}

Muito se fala da importância da leitura na formação humana e identitária dos sujeitos. Os argumentos vão desde os mais utilitários, que julgam ser essa prática uma necessidade de informação e conhecimentos para garantir um futuro, até, nos casos mais utópicos, a crença na leitura como forma de libertação/conscientização tanto individual quanto coletiva.

Com o intuito de discutir acerca dos que defendem a ideia de que a leitura é importante para a fruição, ou para desenvolver aspectos da escrita ou, ainda, pra ter conhecimentos acumulados e, assim, elevar o portador destes conhecimentos ao nível de intelectualidade exigido pela sociedade para dar-se bem na vida, cabe trazer presente os apontamentos do pesquisador espanhol Jorge Larrosa (2016), que defende a ideia de que toda a leitura que fazemos deve ser uma experiência, contudo, as verdadeiras e mais profundas experiências de leitura acontecem quando não têm finalidade alguma. A partir do momento que são "para" alguma coisa ou "para atingir um determinado objetivo", ela deixa de ser experiência. E, se não temos experiências com as leituras que lemos, nada nos passa, nada acontece em nós, por isso, são vazias de sentido.

Estamos inseridos em uma sociedade que nos exige gerar resultados a todo o momento, por isso, não temos tempo para atividades inúteis como ler sem pressa, deliciando-se com cada metáfora, com cada construção bem feita, com cada história emocionante ou questionamento subentendido em cada palavra, ou para ouvir música curtindo cada arranjo ou, então, sair dançando com os pássaros enquanto recita uma poesia. Caminhar devagar observando as pessoas e a paisagem está cada vez mais raro de se ver. Ouvir uma música ou ler um livro sentado em um banco de praça, a sentir a energia do lugar e das pessoas que por ali passam, é para poucos. Não temos tempo. Não nos dão tempo. Não nos permitem este tempo. Com passos apressados saímos e retornamos para nossas casas-gaiola todos os dias, porque não temos tempo. Rapidamente, conversamos com amigos e colegas sem nos prender muito aos assuntos, porque não temos tempo. Ouvimos músicas no fone de ouvido enquanto caminhamos com o cachorro, ou limpamos a casa, ou corremos na esteira, ou, ou...

Outra constatação é a de que, sim, lemos muito. Enquanto estamos no transporte coletivo ou no intervalo de um período de trabalho ou de estudo, lemos. Somos os leitores ubíquos de que fala Lúcia Santaella (2013), os que transitam por inúmeros textos ao mesmo tempo estando em diferentes lugares. Contudo, essa ubiquidade pode ser uma armadilha para não termos experiências, porque não damos tempo para as coisas inúteis, tão necessárias para manter alta nossa dose de humanidade. A utilidade do inútil nunca fez tanto sentido como nos últimos tempos. Nesse sentido, o pesquisador italiano Nuccio Ordine (2016) aponta o quanto as atividades sempre consideradas inúteis pela 
sociedade capitalista podem fazer a diferença em momentos de crise.

Ao mencionarmos as situações de crise, cabe trazermos à tona as pesquisas de Michèle Petit (2009) ao destacar que todos, em alguma circunstância da vida, vivemos ou enfrentamos momentos de crise e que o contato com os livros e as leituras é uma das formas de enfrentarmos e encontrarmos saídas possíveis para nossos impasses. Ao encontro desse pensamento está o direito à literatura, defendido por Antonio Candido (2017) quando diz que devemos democratizar o acesso à literatura assim como o direito à saúde, à alimentação, à moradia. Contudo, infelizmente, vivemos em um país que não cuida, não educa e tampouco alimenta fisicamente seu povo, assim, não podemos esperar que a leitura seja escolhida e valorizada como uma atividade de primeira necessidade.

Assim, ao nos depararmos com todas essas discussões acerca da leitura e das necessidades urgentes que vemos em difundi-la e democratizá-la, queremos apontar neste artigo algumas ações que realizamos durante o período da pandemia, em 2020, junto aos grupos que chamamos de habitantes dos espaços de crise, assim nominados por Petit (2009), e com estudantes de duas escolas da rede pública da cidade de Feliz/RS. Tratam-se de ações de mediação de leitura realizadas junto a meninos que cumpriam medidas socioeducativas no Case Caxias do Sul/RS, com o apoio dos professores, oficineiros e equipe técnica da instituição, e com estudantes do ensino básico que realizavam aulas remotamente e/ou de modo híbrido naquele período. Destacamos que cumprimos, durante a realização das ações e também na escrita deste artigo, os preceitos éticos de garantir o anonimato dos sujeitos envolvidos, bem como o respeito às suas opiniões e privacidade. Com os adolescentes em privação de liberdade, firmamos, ainda em 2019, um documento de parceria entre as instituições (IFRS e Case) que nos garante e permite a realização das ações desde que se respeitem os direitos garantidos pelo Estatuto da Criança e do Adolescente e as regras internas da instituição. Com os estudantes da rede pública de Feliz/RS, por estarem em atividades remotas e utilizarem o espaço online para as aulas, as escolas possuem autorizações de uso de imagem e voz, porém, da mesma forma que agimos com os meninos do Case, também preservamos suas identidades.

Por se tratar de um trabalho que discute ações relacionadas à leitura, adentramos no campo do imponderável. Assim, percepções e subjetividades são a essência para as reflexões que aqui travamos, embasados na discussão de dados qualitativos coletados e organizados a partir de uma pesquisa que, de acordo com Thiollent (1986), requer pesquisa e ação. Isso porque, na medida em que se descobrem determinadas situações, também é possível alterar a prática cotidiana dos envolvidos. O método de observação participante para a coleta de dados usados para as discussões deste trabalho teve, então, a participação atuante dos mediadores, que são a equipe do projeto, os quais puderam, 
então, avaliar suas práticas ao mesmo tempo em que participaram delas.

O planejamento das ações que este artigo discute levou em conta as necessidades e interesses dos grupos envolvidos. Dessa forma, juntamente com as equipes das instituições participantes, a coordenadora e bolsistas do projeto prepararam as ações de mediação leitora que foram realizadas com os grupos de adolescentes, levando em consideração três principais eixos norteadores: a observação e coleta de informações iniciais a partir da conversa com os envolvidos no planejamento; a exploração, a análise e a interpretação a partir da realização de cada atividade e, por fim, a avaliação do resultado final a partir do que cada grupo produziu, a partir das ações. Assim, este texto apresenta, a partir dos resultados que colhemos, uma discussão que mescla conceitos teóricos acerca da leitura e da mediação com as observações colhidas pelos mediadores durante as ações.

Como principal objetivo deste texto, destacamos o propósito de apresentar o resultado desses dois trabalhos de mediação leitora realizados junto a adolescentes e mediadores de leitura em um momento de crise sanitária global. Assim, trabalhar com escritos de Machado de Assis (O espelho) e de Carlos Drummond de Andrade (E agora, José?) como proposta de mediação leitora foi a estratégia utilizada a fim de contribuir para o processo humanizador da literatura junto aos grupos com os quais foi realizada a ação. Como objetivos específicos, destacam-se a possibilidade de discutir o importante papel da leitura literária na formação humana, à luz das teorias da leitura e da formação do leitor e, também, apresentar o resultado de ações de mediação leitora com estudantes de escola pública em estudo remoto e com adolescentes privados de liberdade durante a pandemia.

Dessa forma, a organização deste texto compreende, ao mesmo tempo em que descreve as ações realizadas, o cruzamento entre as teorias que sustentam e apontam as descobertas de cada mediação leitora. As atividades, baseadas em dois textos canônicos e de gêneros diferentes - O espelho, de Machado de Assis, e E agora, José?, de Carlos Drummond de Andrade -, foram as pontes de afeto construídas para aproximar leitores e contribuir para as reflexões que possam surgir a partir das necessidades específicas de cada grupo, habitante de cada espaço em crise.

\section{A LEITURA E A LITERATURA COMO DIREITO HUMANO}

As instituições públicas federais de ensino, principalmente os Institutos Federais, têm a obrigação de estar junto à comunidade a fim de reconhecer suas necessidades e, de alguma maneira, inserir-se nela a fim de contribuir, de buscar formas de interação que gere conhecimento. Nesse sentido, desenvolver projetos de ensino, extensão e pesquisa junto aos grupos locais e regionais são de extrema importância. Contudo, a construção deve ser coletiva, partindo de suas necessidades reais. 
Por conta da sobrecarga de trabalho remoto e dificuldades de acesso a mecanismos digitais, muitas instituições escolares se encontram perdidas e desamparadas no que diz respeito ao trabalho com a leitura e às produções/criações/possibilidades a partir dela. Assim, o projeto desenvolvido pelo IFRS - Campus Feliz, denominado Experiências de leitura em espaços de crise realizou ações remotas de mediação de leitura do conto O espelho, de Machado de Assis, com alunos de Ensino Médio da própria instituição em conjunto com os de nono ano de uma escola municipal da cidade, e o texto poético E agora, José?, de Carlos Drummond de Andrade, com um grupo de adolescentes em privação de liberdade do Centro de Atendimento Socioeducativo - Case - de Caxias do Sul.

A escolha das leituras para a ação levou em conta o fato de que textos canônicos não podem ser afastados dos adolescentes (estudantes ou não, leitores ou não) por serem considerados de difícil acesso/compreensão. É preciso literaturizar os espaços escolares e a instituição socioeducadora, dando possibilidades de acesso ao literário a fim de que possam, através dessa aproximação, perceber que há muito de cada leitor naquilo que lê, e que a literatura não está dissociada do seu mundo real, por pior que ele possa parecer ou sentir.

Assim, a proposta de levar Machado de Assis e Carlos Drummond de Andrade aos adolescentes vai ao encontro do que propõe a BNCC (BRASIL, 2018). O documento aponta a necessidade de ampliar a leitura dos clássicos na escola estabelecendo uma abordagem dialógica e comparativista entre diferentes textos, além de enfatizar a importância deles em si, em relação aos períodos literários aos quais estão vinculados. Acreditamos na ideia de que a escolha dos textos por nós trabalhados possa ser de muito proveito para os estudantes, pois, de acordo com Annie Rouxel (2013), o conteúdo existencial de uma obra deixa marcas importantes que contribuem para que tenham um ganho ético e estético, simultaneamente, como é o caso de $O$ espelho e do E agora, José?. Isso porque os textos, considerados clássicos, dialogam com o nosso tempo. Como explica Ítalo Calvino (1996), ao definir o termo: "13. É clássico aquilo que tende a relegar a atualidade à situação de rumor de fundo sem, no entanto, extinguir esse rumor. 14. É clássico aquilo que persiste como rumor de fundo exatamente onde a atualidade que está mais distante reina soberana" (CALVINO, 1996, p. 15).

É através do diálogo entre o passado e o presente que está o ponto de interesse dos jovens. Possibilitar que se vejam no espelho machadiano, ou no José, de Drummond, na atualidade, é tarefa do professor-mediador que é convocado a, com sua inventividade, elaborar dispositivos capazes de

\footnotetext{
${ }^{1}$ Projeto cadastrado no sistema Sigproj com o número 346653.1931.164570.11022020, aprovado no EDITAL IFRS nº 65/2019 - Registro de ações de extensão Fluxo Contínuo 2020.
} 
interpelar os alunos para a leitura. Mostrar que essas obras escritas há alguns anos podem dizer algo aos jovens do século XXI que estão privados ou com liberdade limitada e restrita, seja por conta da pandemia ou de delitos praticados, é o desafio que nos propomos com esta atividade.

A abordagem de mediação dos textos foi escolhida, pensada, programada pela equipe que organizou a ação de extensão, juntamente com a contribuição do professor da turma de nono ano da escola de Feliz/RS e com as professoras da escola do Case, equipe técnica e as oficineiras de bordado. Com planejamento prévio e a ação conjunta, o diálogo entre mediadores, jovens, textos, espaços e autores aconteceu e amarrou os fios e os pontos que se transformaram em arte nesta quarentena.

A ação com o texto machadiano teve a leitura prévia pelos alunos com a orientação dos extensionistas e do professor, que auxiliou na mediação, solicitando uma leitura silenciosa, com estudo do vocabulário. Também foi sugerida a leitura na frente do espelho, com pausas para olhar e pensar. Como diz Larrosa (2003), para a experiência acontecer é preciso ler devagar, pensar devagar, ou seja, tirar a velocidade dos nossos hábitos e pausar para viver a verdadeira experiência com o texto. O propósito foi de que, sem que o mediador dissesse, cada um pudesse olhar para dentro de si e perceber qual era sua verdadeira imagem refletida no espelho. Posteriormente, em momento síncrono, via sala do Google Meet, os alunos das escolas de Feliz/RS, que realizaram a leitura de O espelho, conversaram sobre o que leram e as possibilidades de relações com outros elementos semióticos que dialogam com o texto machadiano. Apresentamos (e conversamos sobre) pinturas que destacavam a imagem de pessoas refletidas no espelho, citamos o filme Alice através do espelho, questionamos sobre outras possíveis relações da temática com obras que conhecessem. Com um espelho em mãos, através da tela do computador, a mediadora, coordenadora do projeto, declamou o poema Retrato, de Cecília Meireles, e conversamos sobre quem somos, quem fomos e para onde vamos.

A possibilidade de relações com as redes sociais e a influência que elas têm na vida das pessoas, principalmente o Instagram e os jovens, surgiu a partir da conversa. Imagens de famosos e seu dia a dia, em sua "normalidade", e também "projetadas no espelho mágico do Instagram" vieram à tona. As discussões permearam a projeção fantasiosa de imagem e de personalidade tão comuns na sociedade do espetáculo que vivemos hoje, principalmente, em época pandêmica. Alguns exemplos de como as pessoas podem esconder dores e lamentações ou, então, fugir de sua realidade através de perfis que espelham uma vida fictícia apenas para agradar os outros e se afirmar como pertencente a um grupo foram citados.

A ação também objetivou a ampliação do contato com o texto para além do estudante, envolvendo, também, sua família. Assim, quando fizessem esse encontro da família com a palavra 
em forma de arte literária, pedimos que os estudantes escolhessem uma frase do texto que tivesse atraído sua atenção para, em um pedaço de pano (uma tela), traçar um bordado que representasse nosso encontro machadiano da quarentena. Para auxiliar na tarefa, convidamos uma ex-aluna da escola, hoje artista da arte do bordado, para ensinar alguns pontos para os estudantes. Esse processo de construção, primeiramente individual, transformou-se em um trabalho coletivo, em um grande espelho representativo dessa leitura machadiana elaborado em período pandêmico. Assim, acreditamos que os estudantes, movidos pela beleza do texto literário e das ideias que surgem a partir dele, verão em outras leituras oportunidades para o encontro, o acolhimento, o afeto e a criação; acreditamos que a conversa sobre livros e leituras não será delegada apenas como tarefa escolar, mas que será aberta ao entendimento do mundo à nossa volta com suas múltiplas possibilidades.

Figura 1 - Fios e nós machadianos

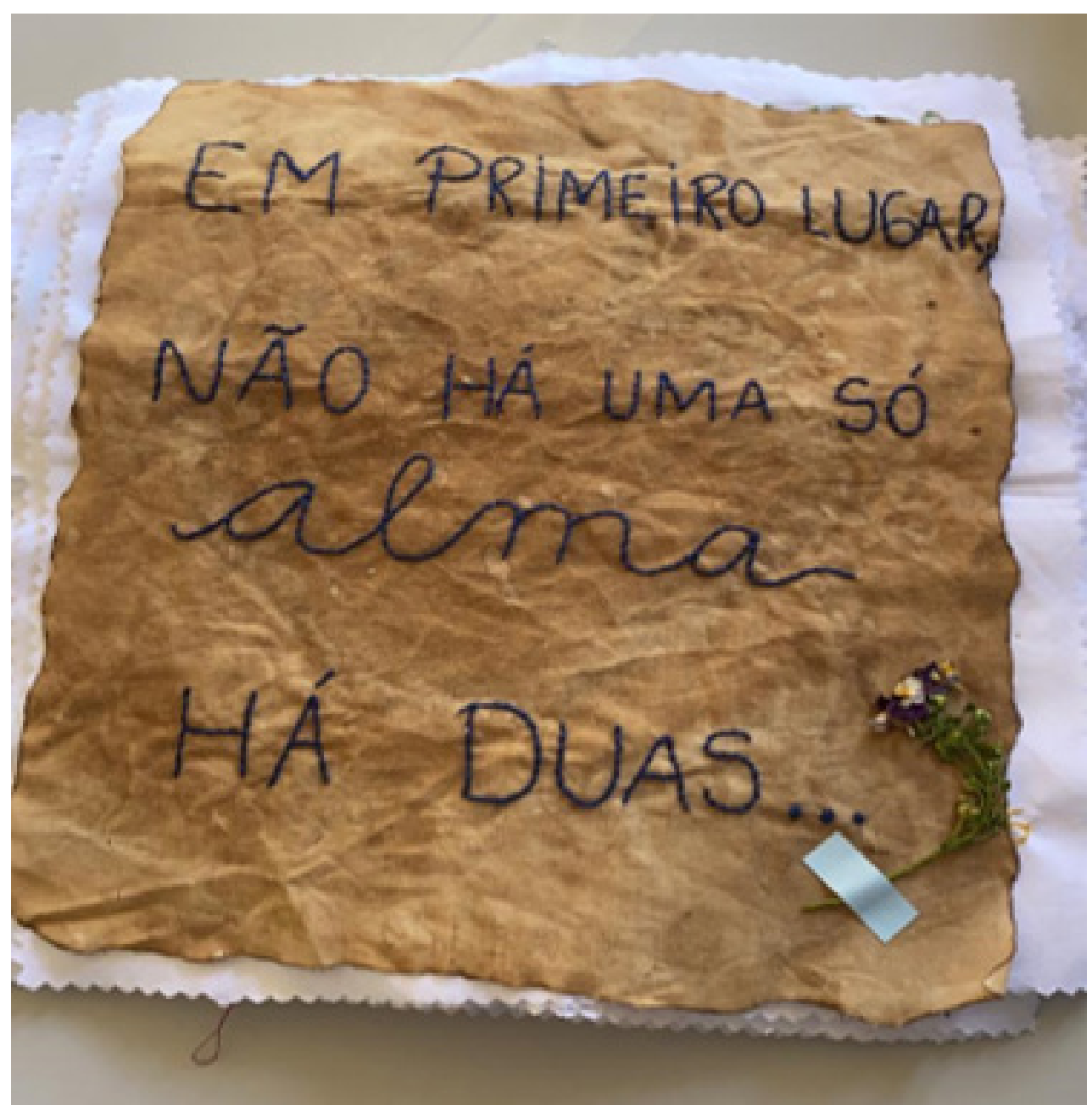

Fonte: Arquivo do projeto (2021). 
Quando Petit (2009) declara que os livros e as histórias são portas e pontes de afeto para a reconstrução de cada leitor que vive em espaços/situações de crise, podemos, com a ação de leitura no Case Caxias do Sul/RS, afirmar que ela tem toda a razão. Os meninos que cumpriam medidas socioeducativas naquela instituição, no segundo semestre de 2020, além de privados de liberdade estavam, também, privados do contato com seus familiares e outras ações presenciais coletivas que a casa anteriormente fazia. A pandemia se mostrava para eles como mais uma das tantas formas de opressão com que tinham que lidar.

Nosso projeto já atuava naquele espaço em anos anteriores. Víamos, então, a necessidade de estar novamente junto àqueles com os quais poucos querem ou têm coragem de estar. Assim, nos reunimos virtualmente com a equipe técnica e com os professores que, em outubro, retornaram, remotamente, suas aulas na instituição a fim de pensar em estratégias de como tocar cada garoto com a palavra em forma de arte, de modo que eles pudessem se sentir acolhidos e também acolher o texto como elemento (trans)formador de si e do mundo à sua volta. Ao optarmos pelo texto poético E agora, José?, de Carlos Drummond de Andrade, vimos a musicalidade e o ritmo do texto como aliados para o primeiro contato. Assim, através de vídeos de rappers musicando o poema e com declamações que acentuavam a tonicidade, ganhamos a atenção dos garotos. A leitura silenciosa e oralizada do poema aproximou ainda mais os jovens leitores do texto literário, sempre tão afastado dos espaços não formais de leitura. Auxiliamos remotamente as professoras na organização das oficinas de leitura e discussão do texto que realizavam com os adolescentes que, a cada encontro, se mostravam mais próximos do texto. Iam, aos poucos, reconhecendo o José que havia dentro de cada um e a necessidade que tinham de responder à pergunta que não calava: E agora, José?

Como acreditamos que a leitura, quando está cumprindo com seu papel humanizador, apresenta possibilidades de interação que ultrapassam a simples lógica do texto, quisemos saber como os adolescentes privados de liberdade, em período de quarentena, responderam a essa questão, assumindo, então, a posição de Josés. Com a orientação das oficineiras de bordado que retomavam, naquele mês primaveril, suas atividades na instituição, os garotos se encheram de esperança, de poesia e de força drummondiana para responderem ao questionamento que, há mais de setenta anos, o poeta nos faz: E agora, José? Cada resposta foi bordada em um pequeno pano que, unido a outro pano, compôs o grande mosaico de pontos, fios e nós da quarentena. 
Figura 2 - "E agora, José?" - Mosaico de pontos, fios e nós da quarentena



Fonte: Arquivo do projeto (2021).

A literatura, em sua essência, é um direito humano fundamental. Dizemos isso, pois acreditamos que a literatura possui o poder de interferir na vida de um leitor através de seu poder humanizador e transformador, que auxilia na formação identitária e no exercício da compreensão de si e do outro enquanto ser pertencente a uma sociedade.

Ao trabalharmos com a mediação de leitura, principalmente tendo como foco os grupos mais vulneráveis e que habitam espaços não formais de leitura, trazemos presente o pesquisador Antonio Candido (2011) e sua defesa da leitura como ato humanizador. Assim, vemos a literatura como um direito incompressível, ou seja, imprescindível para o ser humano, pois é a manifestação universal de todos os tempos, de todos os povos. É a expressão singular de cada cultura, de cada sujeito pen- 
sante, que ressignifica sua realidade através da ficção. Além disso, a literatura fomenta em nós as emoções, através de sua estética, e o pensamento crítico, na medida em que analisa o mundo real e o retifica em palavras, nos pondo à frente dos problemas sociais. É, portanto, dessa forma, que a literatura possui um poder de humanização importantíssimo, definido por Antonio Candido (2011), como um

processo que confirma no homem aqueles traços que consideramos essenciais, como o exercício da reflexão, a aquisição do saber, a boa disposição para com o próximo, o afinamento das emoções, a capacidade de penetrar nos problemas da vida, o senso da beleza, a percepção da complexidade do mundo e dos seres, o cultivo do humor. A literatura desenvolve em nós a quota de humanidade na medida em que nos torna mais compreensivos e abertos para a natureza, a sociedade, o semelhante (CANDIDO, 2011, p. 179).

Assim, acreditamos que esse poder que a literatura possui age através da relação de alteridade entre memórias, livros e histórias que o ato de ler proporciona, pois, por meio desse diálogo, somos convidados a resgatar nossas memórias e a repensar a nossa própria identidade. No texto escrito pelo outro, reconhecemos um alguém que, por vezes, pensa diferente de nós. Assim, tolerando e respeitando o discurso proferido pelo outro, repensamos sobre o que realmente somos, encontramos o nosso próprio texto no escrito produzido pelo próximo e reconhecemos nossa própria identidade.

Quem lê, o faz com toda sua bagagem de vivências pessoais, seus interesses e suas vontades. Logo, os textos e memórias, livros e leitores, entrelaçam-se, possibilitando que o leitor olhe para dentro de si mesmo, reconheça-se como um sujeito importante para o meio em que vive e, talvez, possa apaziguar suas inquietações - estando aí o poder transformador da leitura. É, portanto, nesse universo de discussões acerca da leitura que nos encontramos com os dizeres do pesquisador espanhol Jorge Larrosa (2003), que aponta para a perspectiva da "leitura como algo que nos forma (ou nos deforma ou nos transforma), como algo que nos constitui ou nos questiona acerca do que somos" (LARROSA, 2003, p. 25. Tradução nossa).

Ao mencionarmos Larrosa (2003), acreditamos ser importante ressaltar a sua definição acerca da leitura como experiência. Para o teórico espanhol, a "experiência seria aquilo que nos passa. Não o que passa, senão o que nos passa" (Ibid., p. 12). O importante, portanto, é aquilo que realmente 
sentimos, pensamos e imaginamos ao ler determinadas palavras, frases e pensamentos contidos nas linhas do papel. Aquilo que nos passou, nos tocou. Assim, a leitura que é feita apenas para adquirir conhecimentos, ou para isso ou aquilo, com um fim que não seja ela mesma, sem levar em conta o que nos passou durante e após a leitura, não se configura como uma experiência, pois "não resulta na formação ou na (trans)formação do que somos" (LARROSA, 2003, p. 13).

Ao encontro dessa mesma concepção de leitura, a professora pesquisadora Eliana Yunes (2003) afirma que o ato de ler é um "ensaio de vidas" (YUNES, 2003, p. 14), pois permite que viajemos para outros mundos, experienciemos diferentes sentimentos e conheçamos diferentes perspectivas da vida. Assim, a leitura como experiência torna-se uma forma de exercitarmos nossa subjetividade e aquilo que temos de mais humano, pois permite que "o sujeito se experimente e se transforme enquanto transforma o texto" (Ibid., p. 14). Encontrar o mais humano de cada um é encontrar pessoas por dentro das pessoas. No caso dos adolescentes privados de liberdade que cumprem medidas socioeducativas, notamos que essa necessidade do encontro é ainda maior do que com os outros estudantes com os quais desenvolvemos a atividade. Isso porque estar experienciando um momento de crise em um espaço de socioeducação representa, na maioria das vezes, uma punição. Assim, levar um texto canônico até estes garotos, em um espaço não formal de leitura (centro socioeducativo), representa dar-lhes o direito ao acesso àquilo que, talvez, ele nunca tenha tido e essa negação possa ter contribuído para a abertura da porta aberta dos delitos.

O que nos fica claro, então, a partir destes diálogos que aqui travamos com as teorias acerca da leitura, é que sua forma utilitária não cabe na experiência, pois ela se configura para além do ler para aprender. É dialogar com o texto, deixar-se levar pelas palavras, permitir que a mente voe juntamente com a leitura, e, de acordo com a bagagem de cada um, atribua novos significados às frases. Nesse sentido, em um período em que o mundo vive uma pandemia e todos os agravamentos que ela traz, é urgente perceber na leitura literária e toda sua carga de inutilidade (ORDINE, 2016), uma forma de suspensão, porém, não vazia e superficial, mas como uma possibilidade de voltar o olhar para dentro de si e (re)encontrar-se enquanto ser individual. Isso porque, ao atribuirmos novas significações ao texto, ressignificamos a nós mesmos, pois, através do diálogo estabelecido entre livro e leitor, quem lê é convidado a voltar o olhar para dentro de si, a refletir sobre seus conceitos, sobre o que leu e acabou de ressignificar. Assim, nessa viagem até as profundezas de si, o leitor estabelece diferentes perspectivas sobre suas próprias ideias, pensamentos e até sobre os seus dias. Nesse sentido, Eliana Yunes (2003) teoriza que 
A leitura $[\ldots]$ passou a ser um precioso instrumento de reaproximação à vida, pelo qual o deslocamento de horizonte provocado pelo texto, pela interação que mobiliza o sujeito do desejo, ressitua o leitor e faz com que ele possa atualizar o texto no ângulo da sua historicidade, da sua experiência, dando-lhe também nova vida (YUNES, 2003, p. 11).

Se cada leitor traz sua experiência para o momento da leitura e atualiza o que lê, de acordo com sua bagagem interior, os mediadores são, inegavelmente, muito importantes nesse processo de atualização. Principalmente, quando essa mediação ocorre nos espaços não formais de leitura ou, então, quando esses leitores se encontram nos espaços de crise. Nesse sentido, nos amparamos nos escritos da pesquisadora francesa Michèle Petit (2009) e os seus estudos sobre os denominados espaços de crise. A autora utiliza essa terminologia para tratar de lugares que remetem a situações de desconforto ou de sofrimentos transitórios pelos quais passam algumas pessoas em algum momento de suas vidas. Esses contextos sobre os quais discorre variam desde lugares em guerra, situações de violência, exclusão até conflitos familiares. Apesar de alguns espaços de crise serem mais duradouros, mais tristes ou cruéis que outros, todos remetem a cenários de dor, de privações, pelas quais, em algum momento, vamos nos confrontar. Conforme afirma Petit (2009),

Cada um de nós é um espaço em crise. Os seres humanos têm, diga-se de passagem, uma predisposição originária, antropológica, à crise: nascemos prematuros, nós somos marcados por uma fragilidade cujos vestígios permanecem ao longo da vida. Porém, saídas nos são oferecidas para que não sejamos atingidos pelos componentes destrutivos daquilo com que somos confrontados (PETIT, 2009, p. 33).

O que percebemos, então, é que as saídas para as crises apontadas pela pesquisadora são as ideias. Somente elas, de certa maneira, podem nos libertar das aflições, dos medos, na medida em que modificam ações nocivas ao nosso ser, tornando-as um potencial transformador que libera alegria e nos permite voltar a sonhar, a imaginar, a potencializar ações positivas. Essas ideias são ligadas intimamente aos livros e à leitura, pois "os livros nos ajudam algumas vezes a manter a dor ou o medo à distância, transformar a agonia em ideia e a reencontrar a alegria” (PETIT, 2009, p. 34).

Nesse sentido, o que se desenhou como resultado desta ação é, sem sombra de dúvidas, um 
trabalho pensado coletivamente e realizado com o apoio de muitas mãos e corações. Mãos que sabem a importância do fazer, do construir, do tentar, do unir e do costurar pedaço a pedaço para compor o todo único em sua diferença e significativo em sua individualidade. Corações que, por transbordarem amor e afeto, acreditam nas pessoas como possibilidades, como (re) construções.

Assim, as muitas respostas dos tantos Josés para a pergunta drummondiana se somarão às impressões dos leitores machadianos e, juntos, farão a composição do grande mural dos afetos do projeto de extensão, realizado durante a quarentena. Promover a leitura neste período, com um público com realidades tão distintas - uns estudantes em aulas remotas, na segurança de seus lares, outros cumprindo medida socioeducativa, na inconstância de saber sobre seu futuro - e com características tão iguais: são adolescentes e jovens com sonhos, desejos, medos e anseios - ao mesmo tempo, aponta para a urgente necessidade de literaturizar os espaços coletivos como forma de promover a humanização que nos salva da ignorância e da alienação.

Portanto, a ação de mediação de leitura que realizamos no Centro Socioeducativo (Case de Caxias do Sul) e com os estudantes da rede pública de Feliz/RS, em um momento em que os encontros presenciais eram limitados, nos mostraram que as experiências com o texto, quando mediadas, podem (trans)formar sentimento em ideia e emoção em arte.

\section{CONSIDERAÇÕES FINAIS}

Somos sabedores de que a leitura de textos literários bem como a participação/envolvimento nas mais diversas manifestações artísticas despertam emoções e mergulhos nas memórias interiores dos leitores. O envolvimento com a palavra em forma de arte muda o pensar, redimensiona o olhar e até permite a suspensão do tempo e do espaço reais para transportar-se para outros lugares a fim de redescobrir sentimentos e percepções que estão, por ora, adormecidos.

Foi essa a percepção que muitos dos leitores participantes das ações aqui mencionadas tiveram e externaram através das conversas no encontro síncrono e no trabalho artístico final. Na ação dos meninos do Case, foi o poema drummondiano um meio para que os habitantes daquele espaço de crise desviassem, de forma sensível, o curso de suas então confinadas vidas e, assim, pudessem repensar acerca de suas relações consigo mesmos e com o mundo. Foram abertas, assim, possibilidades de projetar uma ideia de futuro, através da contestação da pergunta que o texto, insistentemente, faz ao leitor que, ao se sentir tocado, não contente em apenas responder, também pega a chave e "foge a galope" sabendo muito bem onde está a porta que quer abrir. Já os jovens estudantes das escolas de Feliz/RS prenderam-se na teia machadiana e encontraram-se na liberdade da pala- 
vra que envolve e que liberta, que faz pensar e que desperta. A projeção da imagem de cada um no espelho da teia social na qual estão involucrados declara: "Em primeiro lugar não há uma só alma, há duas" (ASSIS, 1994, p. 2). Ao pensarem acerca das imagens que projetam de si mesmos, diariamente, a fim de suprir seus anseios e/ou daqueles a que querem agradar, notam que o ser humano é múltiplo, é multifacetado e que, conforme a situação, usa a máscara social que melhor lhe convém.

Por isso, longe de estabelecer uma consideração final, diante do que se pode ver, ouvir e sentir em cada relato e escrita, constatamos que as ações de leitura realizadas, em particular estas aqui mencionadas em maiores detalhes, permitiram, de alguma maneira, a saída do lugar comum e a criação de perspectivas: nos adolescentes em cumprimento de medidas socioeducativas, apaziguar a dor da privação de liberdade ao mesmo tempo em que se aproximam de si mesmos e de seus sonhos e, através do texto, colocarem-se em marcha; nos jovens de Feliz/RS, o espelho onde projetam suas imagens traz, agora, várias versões de si mesmos com as quais precisam lidar e se encontrar.

A literatura mostra-se, então, responsável por estabelecer em nós a quota de humanidade que precisamos para vivermos com alegria e sabedoria. Além disso, possui o poder transformador, que impulsiona mudanças na vida daqueles que se permitem abrir a porta e olhar-se no espelho. Consideramos, então, a literatura como um direito indispensável. Por isso, as ações desenvolvidas pelo projeto Experiências de leitura em espaços de crise, neste ano de pandemia, buscaram garantir que a literatura fosse levada a diferentes espaços de aprendizagem, sejam eles formais ou não formais, principalmente, àquela parcela de adolescentes que não teve oportunidades anteriores de contato com a palavra literária que move e co-move. Assim, com o propósito de oferecer, disponibilizar e de não mais negar este direito àqueles tão distantes desta arte da palavra, é que nos propomos a desenvolver estas ações com responsabilidade pedagógica e muito afeto.

\section{REFERÊNCIAS}

ASSIS, Machado de. Obra Completa. Rio de Janeiro: Nova Aguilar 1994.

BRASIL. Ministério da Educação. Base Nacional Comum Curricular. Brasília, 2018.

CALVINO, Ítalo. Por que ler os clássicos. In: Por que ler os clássicos. São Paulo: Companhia das Letras, 1993.

CANDIDO, Antonio. Vários escritos. 6ª ed. Rio de Janeiro: Ouro sobre Azul, 2017. 
LARROSA, Jorge. La experiencia de la lectura. México: FCE, 2003.

LARROSA, Jorge. Tremores: escritos sobre experiência. Tradução de Cristina Antunes e João Wanderley Geraldi. $1^{\mathrm{a}}$ ed. $2^{\mathrm{a}}$ reimp. Belo Horizonte: Autêntica Editora, 2016.

PETIT, Michèle. A arte de ler ou como resistir à adversidade. Tradução de Arthur Bueno e Camila Boldrini. São Paulo: Ed. 34. 2009.

ORDINE. Nuccio. A utilidade do inútil: um manifesto. Tradução de Luiz Carlos Bombassaro. 1a $^{\mathrm{a}}$ ed. Rio de Janeiro: Zahar, 2016.

ROUXEL, Annie. Aspectos metodológicos do ensino da literatura. In: DALVI, Maria Amélia; JOVER-FALEIROS, Rita; REZENDE, Neide Luzia de. Leitura de literatura na escola. São Paulo: Parábola, 2013.

SANTAELLA, Lúcia. Comunicação ubíqua: repercussões na cultura e na educação. São Paulo: Paulus, 2013.

THIOLLENT, Michel. Notas para o debate sobre pesquisaação. In: BRANDÃO, Carlos Rodrigues (Org.). Repensando a pesquisa participante. $3^{\mathrm{a}}$ ed. São Paulo: Brasiliense, 1987. p. 82-103.

YUNES, Eliana. A leitura como experiência. São Paulo: Loyola, 2003 